\title{
Isolation of Phage Lysins That Effectively Kill Pseudomonas aeruginosa in Mouse Models of Lung and Skin Infection
}

\author{
Assaf Raz, ${ }^{\text {a* }}$ Anna Serrano, ${ }^{a}$ Anaise Hernandez, ${ }^{a}$ Chad W. Euler, ${ }^{a, b, c}$ Vincent A. Fischettia \\ aLaboratory of Bacterial Pathogenesis and Immunology, The Rockefeller University, New York, New York, USA \\ bDepartment of Medical Laboratory Sciences, Hunter College, CUNY, New York, New York, USA \\ cDepartment of Microbiology and Immunology, Weill Cornell Medical College, New York, New York, USA
}

ABSTRACT Multidrug resistance (MDR) is rapidly increasing in prevalence among isolates of the opportunistic pathogen Pseudomonas aeruginosa, leaving few treatment options. Phage lysins are cell wall hydrolases that have a demonstrated therapeutic potential against Gram-positive pathogens; however, the outer membrane of Gram-negative bacteria prevents most lysins from reaching the peptidoglycan, making them less effective as therapeutics. Nevertheless, a few lysins from Gramnegative bacterial phage can penetrate the bacterial outer membrane with the aid of an amphipathic tail found in the molecule's termini. In this work, we took a phylogenetic approach to systematically identify those lysins from $P$. aeruginosa phage that would be most effective therapeutically. We isolated and performed preliminary characterization of 16 lysins and chose 2 lysins, PlyPa03 and PlyPa91, which exhibited $>$ 5-log killing activity against $P$. aeruginosa and other Gram-negative pathogens (particularly Klebsiella and Enterobacter). These lysins showed rapid killing kinetics and were active in the presence of high concentrations of salt and urea and under $\mathrm{pH}$ conditions ranging from 5.0 to 10.0. Activity was not inhibited in the presence of the pulmonary surfactant beractant (Survanta). While neither enzyme was active in $100 \%$ human serum, PlyPa91 retained activity in low serum concentrations. The lysins were effective in the treatment of a $P$. aeruginosa skin infection in a mouse model, and PlyPa91 protected mice in a lung infection model, making these lysins potential drug candidates for Gram-negative bacterial infections of the skin or respiratory mucosa.

KEYWORDS cystic fibrosis, Gram-negative bacteria, Klebsiella, lung infection, MDR infections

Deudomonas aeruginosa is an environmental Gram-negative bacterium that exhibits extensive metabolic adaptability, enabling it to thrive in an extraordinary range of niches (1). It is a highly successful opportunistic pathogen causing a wide range of acute and chronic infections (2) and is a leading cause of nosocomial infections worldwide $(3,4)$. Since the early 1990 s there has been an increasing rate of $P$. aeruginosa involvement in serious infections with high mortality rates (5). P. aeruginosa predominantly infects patients with compromised host defenses, such as patients with severe burns, cystic fibrosis (CF), and neutropenia (6). Additionally, many infections initiate from environmental sources (for example, those of CF patients), and thus, it is difficult to prevent the initial colonization/infection of these patients (7). P. aeruginosa is inherently resistant to many antimicrobial classes due to the limited permeability of its outer membrane $(8,9)$. It is also capable of acquiring resistance to all relevant antibiotics through mutations or the acquisition of new genetic material, severely limiting available treatment options (10). For multidrug-resistant (MDR) P. aeruginosa, polymyxins represent the antibiotics of last resort, despite their excessive toxicity (5,

Citation Raz A, Serrano A, Hernandez A, Euler CW, Fischetti VA. 2019. Isolation of phage lysins that effectively kill Pseudomonas aeruginosa in mouse models of lung and skin infection. Antimicrob Agents Chemother 63:e00024-19. https://doi.org/10.1128/AAC.00024-19. Copyright $\odot 2019$ American Society for Microbiology. All Rights Reserved.

Address correspondence to Assaf Raz, Assaf@phagelux.com.

* Present address: Assaf Raz, Phagelux, Wuhan, Hubei, China.

Received 7 January 2019 Returned for modification 5 February 2019 Accepted 15 April 2019

Accepted manuscript posted online 22 April 2019

Published 24 June 2019 
11-13). There is therefore a clear and urgent need for new therapeutics for MDR $P$. aeruginosa.

Lysins are peptidoglycan hydrolases produced by bacteriophages to release progeny phage from an infected bacterial host. At the end of the phage replicative cycle, lysins gain access to the peptidoglycan through a pore, formed in the inner cell membrane by another phage product, the holin, and the resulting peptidoglycan hydrolysis leads to hypotonic rupture of the cell wall and the release of progeny phages (14). Significantly, exogenously added lysin can lyse the cell wall of healthy, uninfected Gram-positive bacteria, producing a phenomenon known as "Iysis from without" (15-18). Gram-negative bacteria, on the other hand, have proven highly resistant to exogenously added lysins due to their protective outer membrane. Thus, the use of lysins in combination with membrane-destabilizing factors is typically required for activity $(19,20)$. In a series of studies, Ibrahim and colleagues demonstrated that a cell wall hydrolase like lysozyme could become externally active against Gram-negative bacteria by adding a hydrophobic tail to the molecule $(21,22)$. Additionally, a small fraction of natural lysins from Gram-negative phage display activity against Gramnegative bacteria when delivered externally, and this activity is attributed to the presence of one or more amphipathic helices in the molecule, responsible for outer membrane permeabilization (23-25). Recently, researchers have used this knowledge to create Artilysins, engineered lysins with added peptides for improved antibacterial activity. By fusing the sheep myeloid 29-amino-acid (SMAP-29) peptide to the endolysin KZ144, these researchers created Art-175, achieving 5-log killing of $P$. aeruginosa (26). In contrast, our labs used a broad screen approach to identify native antibacterial proteins present in Gram-negative bacterial phages. In a screen of Acinetobacter baumannii phage genomic libraries, we identified 21 lysins capable of killing A. baumannii. One of these enzymes, PlyF307, displayed significant killing activity of $A$. baumannii and contained a positively charged C-terminal tail, required for killing activity (27). The charged tail of PlyF307 alone was further engineered, resulting in greatly improved killing of A. baumannii (28). Recently, Larpin et al. identified PlyE146, an Escherichia coli lysin with a charged tail, which showed activity against $E$. coli, $P$. aeruginosa, and A. baumannii at $\mathrm{pH} 6.0$ (29).

Here we used a systematic phylogenetic approach to explore the sequenced genomes of $P$. aeruginosa for phage lysins with homology to PlyF307. We tested a total of 16 lysins from various phylogenetic groups and identified two lysins, PlyPa03 and PlyPa91, to be the best candidates. These enzymes differed from those previously described by displaying substantial activity against a range of Pseudomonas, Klebsiella, Enterobacter, and other Gram-negative bacterial strains. They also had robust activity in a wide $\mathrm{pH}$ range and high salt and urea concentrations. Importantly, these lysins were active in the presence of the pulmonary surfactant beractant (Survanta) and showed significant protection in murine models of Pseudomonas skin and lung infections.

\section{RESULTS}

Identification of $\boldsymbol{P}$. aeruginosa phage lysins based on homology search. To identify phage lysins with bacteriolytic activity against $P$. aeruginosa, we first performed a BLAST search for genes with homology to the Acinetobacter baumannii phage lysin PlyF307 (27) within $P$. aeruginosa genomes available in the NCBI database, resulting in over 100 hits. These were aligned using the MUSCLE algorithm, and a phylogenetic tree was created, revealing several homology groups (see Fig. S1 in the supplemental material). We then selected 11 lysin sequences representing all major groups and produced synthetic DNA for each lysin for subsequent protein expression. To screen for catalytically active lysins, these 11 candidates (PlyPa01, PlyPa02, PlyPa40, PlyPa49, PlyPa58, PlyPa64, PlyPa78, PlyPa80, PlyPa91, PlyPa92, PlyPa96) were inserted into pAR533, a pBAD24-based plasmid with an altered multicloning site. In one approach, strains containing the expression plasmid were grown on plates containing arabinose to promote expression of the protein. Lysins were released from the streaked cells by exposure to chloroform vapor, and catalytic activity was evaluated by overlaying the 
TABLE 1 Summary of lysin activity in preliminary screens

\begin{tabular}{lll}
\hline & \multicolumn{2}{l}{ Lysin activity $^{a}$} \\
\cline { 2 - 3 } Lysin & Colony overlay & Induced lysate \\
\hline PlyPa01 & + & + \\
PlyPa02 & + & + \\
PlyPa40 & + & + \\
PlyPa49 & + & + \\
PlyPa58 & - & + \\
PlyPa64 & + & + \\
PlyPa78 & - & - \\
PlyPa80 & - & - \\
PlyPa91 & + & + \\
PlyPa92 & - & - \\
PlyPa96 & + & + \\
\hline
\end{tabular}

${ }^{a}$ For colony overlays, E. coli colonies expressing various lysins were permeabilized and overlaid with soft agar containing autoclaved $P$. aeruginosa. Alternatively, induced lysates were produced for the various lysins and spotted over a layer of agar containing autoclaved $P$. aeruginosa cells. The presence of a clearing zone is denoted by a plus sign.

plate with soft agar containing autoclaved (to disrupt the outer membrane) P. aeruginosa and examining the formation of clearing zones around the streaked cells (Fig. S2). In a different approach, an induced lysate of the different strains was applied to a plate containing soft agar with autoclaved $P$. aeruginosa, and the degree of lysis was evaluated (for a representative image, see Fig. S3). A summary of the results obtained in this initial screen is presented in Table 1. The results of the two methods were consistent, with one exception (activity for PlyPa58 was observed only using the crude lysate method). Lysins demonstrating peptidoglycan hydrolase activity in both preliminary screening assays (PlyPa01, PlyPa02, PlyPa40, PlyPa49, PlyPa64, PlyPa91, PlyPa96) were characterized further.

Evaluation of lysin killing activity against $P$. aeruginosa and other Gramnegative organisms. To evaluate the killing activity of the lysins against live $P$. aeruginosa, we produced $3 C$ protease-cleavable hexahistidine tag fusion proteins for those lysins that demonstrated catalytic activity against autoclaved Pseudomonas. These lysins were purified by metal ion affinity chromatography (a representative purification is presented in Fig. S4), and the hexahistidine tag was cleaved by $3 \mathrm{C}$ protease (an example is presented in Fig. S5). In this manner, the final purified and cleaved product contained only 4 additional N-terminal amino acids (Gly-Pro-Val-Asp) compared to the native molecule. We evaluated the ability of purified and $3 \mathrm{C}$ proteasecleaved lysins to kill log-phase P. aeruginosa strain PAO1 (Fig. 1A). Log-phase PAO1 cells were incubated with different lysin concentrations at $37^{\circ} \mathrm{C}$ for $1 \mathrm{~h}$. All lysins demonstrated killing activity to some extent; however, PlyPa01, PlyPa02, PlyPa91, and PlyPa96 had better activity than the others. Of these, PlyPa01 and PlyPa02 were more closely related to the A. baumannii lysin PlyF307, while PlyPa91 and PlyPa96 were more distantly related (Fig. S1).

Examination of the phylogenetic tree revealed a large group of lysins with close homology to PlyPa02. We further explored this group for lysins with improved killing activity by producing lysins PlyPa03, PlyPa09, PlyPa19, PlyPa21, and PlyPa29 in a modified pET21-based plasmid. The lysins were purified and cleaved with $3 C$ protease, and their killing activity against $P$. aeruginosa strain PAO1 was determined as described above (Fig. 1B). These results demonstrated a substantial killing activity for all lysins, with a slight advantage for PlyPa03. The alignment of all lysins tested is presented in Fig. S6. Based on these preliminary results, we chose PlyPa01, PlyPa03, PlyPa91, and PlyPa96 for further characterization.

We next compared the activity of PlyPa01, PlyPa03, PlyPa91, and PlyPa96 against log-phase and stationary (grown overnight) P. aeruginosa cells (Fig. 2). In all cases, stationary bacteria were less susceptible to killing than log-phase cells. However, while the activity of PlyPa01 and PlyPa96 was markedly reduced when used against stationary bacteria, PlyPa03 and PlyPa91 retained substantial killing activity against these cells. 

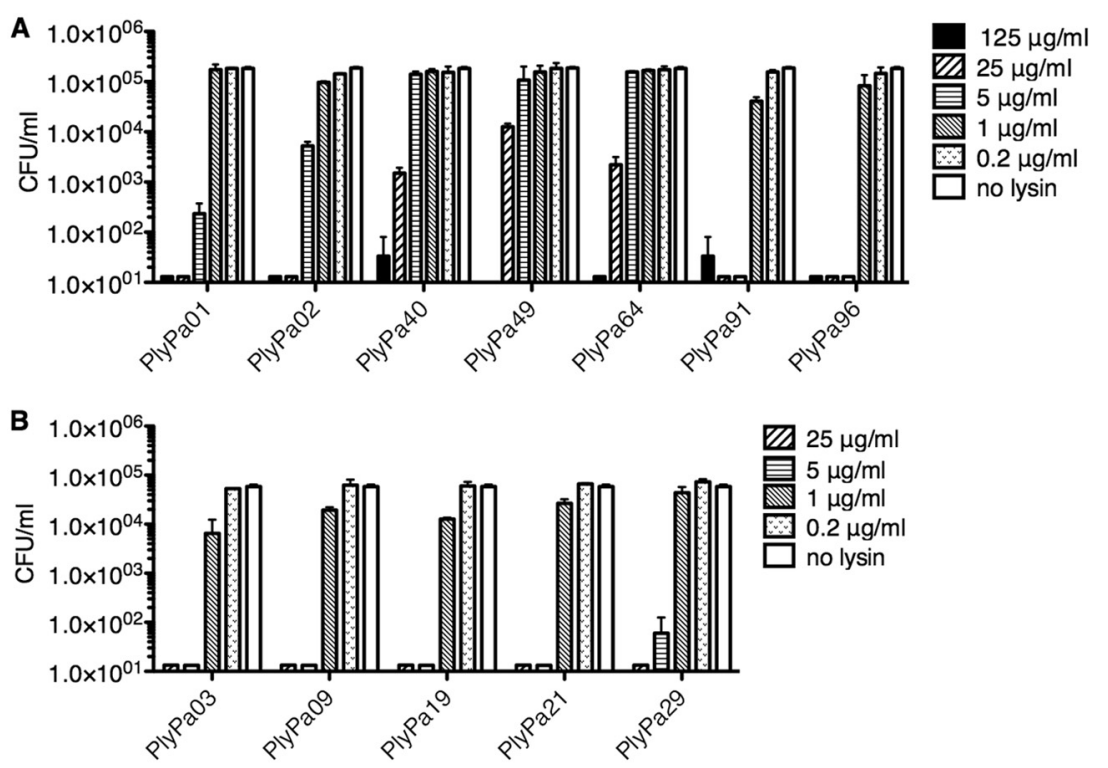

FIG 1 Bactericidal activity of lysins against $P$. aeruginosa PAO1. Purified lysins were diluted to various concentrations and incubated with log-phase $P$. aeruginosa PAO1 for $1 \mathrm{~h}$ at $37^{\circ} \mathrm{C}$ in $30 \mathrm{mM} \mathrm{HEPES}, \mathrm{pH} 7.4$. The values of the number of CFU per milliliter were established by serial dilution and plating. (A) Initial lysins. (B) Additional homologues of PlyPa02. Experiments were conducted in duplicate; error bars represent standard deviations.

We next tested the killing activity of PlyPa01, PlyPa03, PlyPa91, and PlyPa96 at $100 \mu \mathrm{g} / \mathrm{ml}$ against recent clinical isolates of $P$. aeruginosa (Fig. 3A). Following $1 \mathrm{~h}$ of incubation, all four enzymes reduced the colony count of most strains to below the detection level. For AR463, a lower respiratory tract isolate, and AR472, a urinary tract infection isolate, the reduction in viable bacteria ranged from 1 to 4 logs. Both strains were completely eradicated by PlyPa03 at a $250-\mu \mathrm{g} / \mathrm{ml}$ concentration, and the other lysins led to results ranging from complete eradication to a substantial drop in viability at this concentration (Fig. S7).

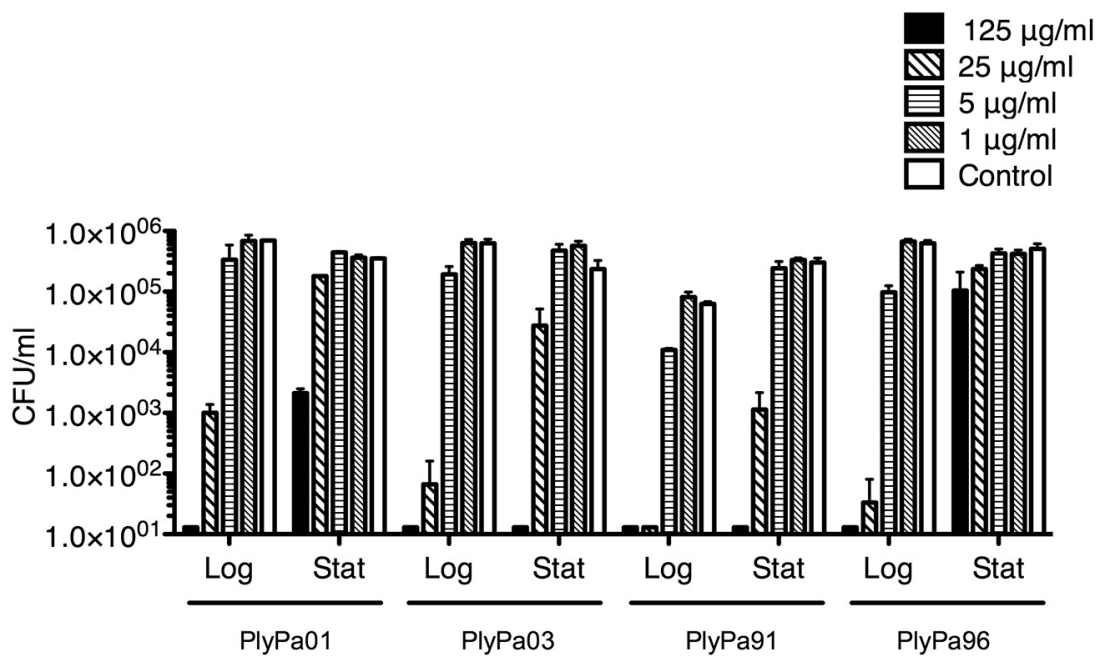

FIG 2 Activity of the lysins against log-phase and stationary $P$. aeruginosa bacteria. The $P$. aeruginosa bacteria were grown overnight (stationary [Stat]), diluted 1:100, and grown to log phase (Log). Bacteria were washed and incubated with lysins at the indicated concentrations in $30 \mathrm{mM} \mathrm{HEPES}$ buffer, $\mathrm{pH} 7.4$, for $1 \mathrm{~h}$ at $37^{\circ} \mathrm{C}$. Viable bacteria were quantified by serial dilution and plating. Experiments were done in duplicate; error bars represent standard deviations. 

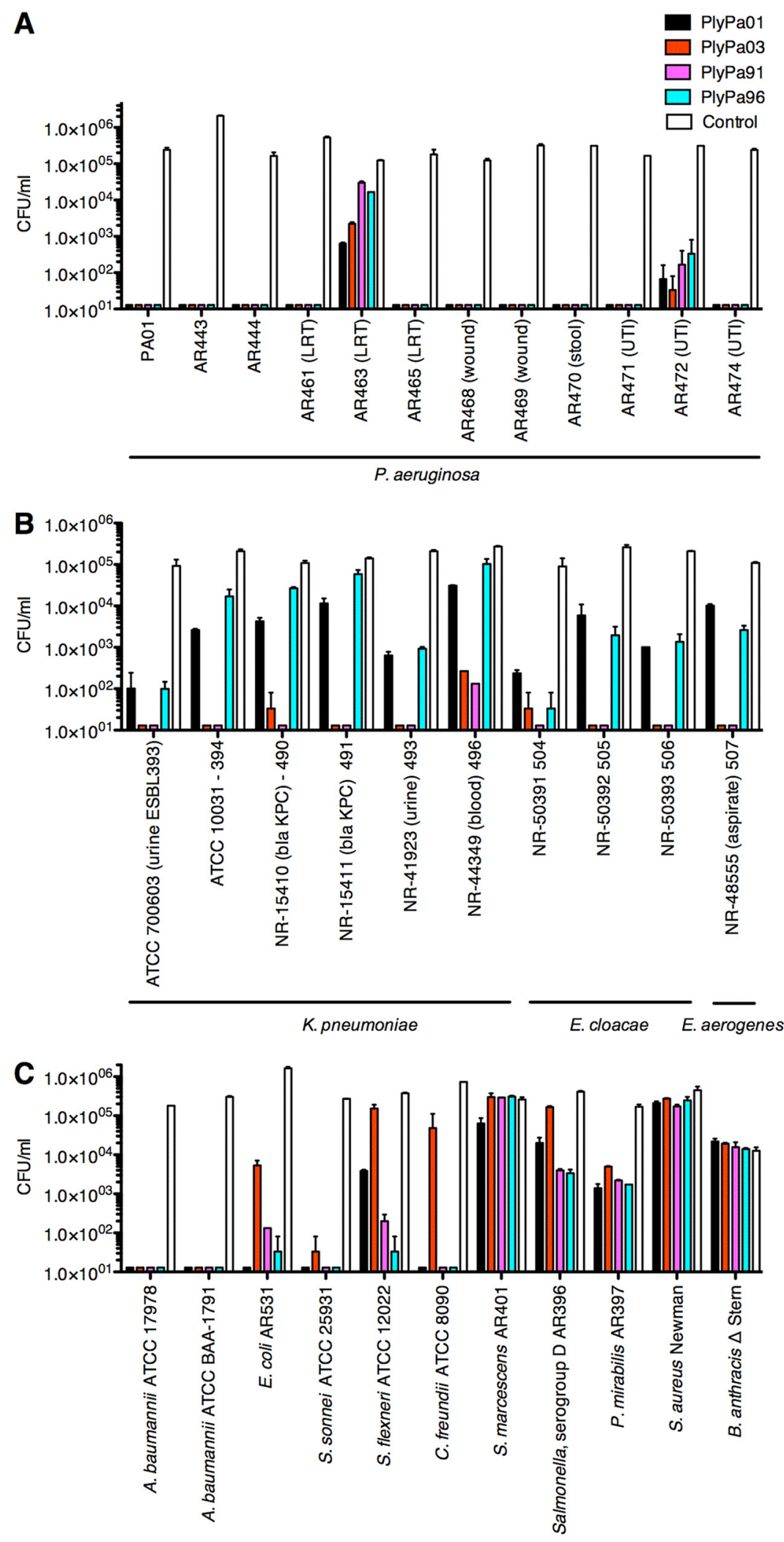

FIG 3 Activity of leading lysins against various bacteria. Various isolates of $P$. aeruginosa (A), Klebsiella and Enterobacter (B), and other Gram-negative and Gram-positive bacteria (C) were incubated with $100-\mu \mathrm{g} / \mathrm{ml}$ lysins in $30 \mathrm{mM}$ HEPES buffer, $\mathrm{pH} 7.4$, for $1 \mathrm{~h}$ at $37^{\circ} \mathrm{C}$. Viable bacteria were enumerated by serial dilution and plating. Experiments were done in duplicate; error bars represent standard deviations. Also see Fig. $\mathrm{S7}$ in the supplemental material. 

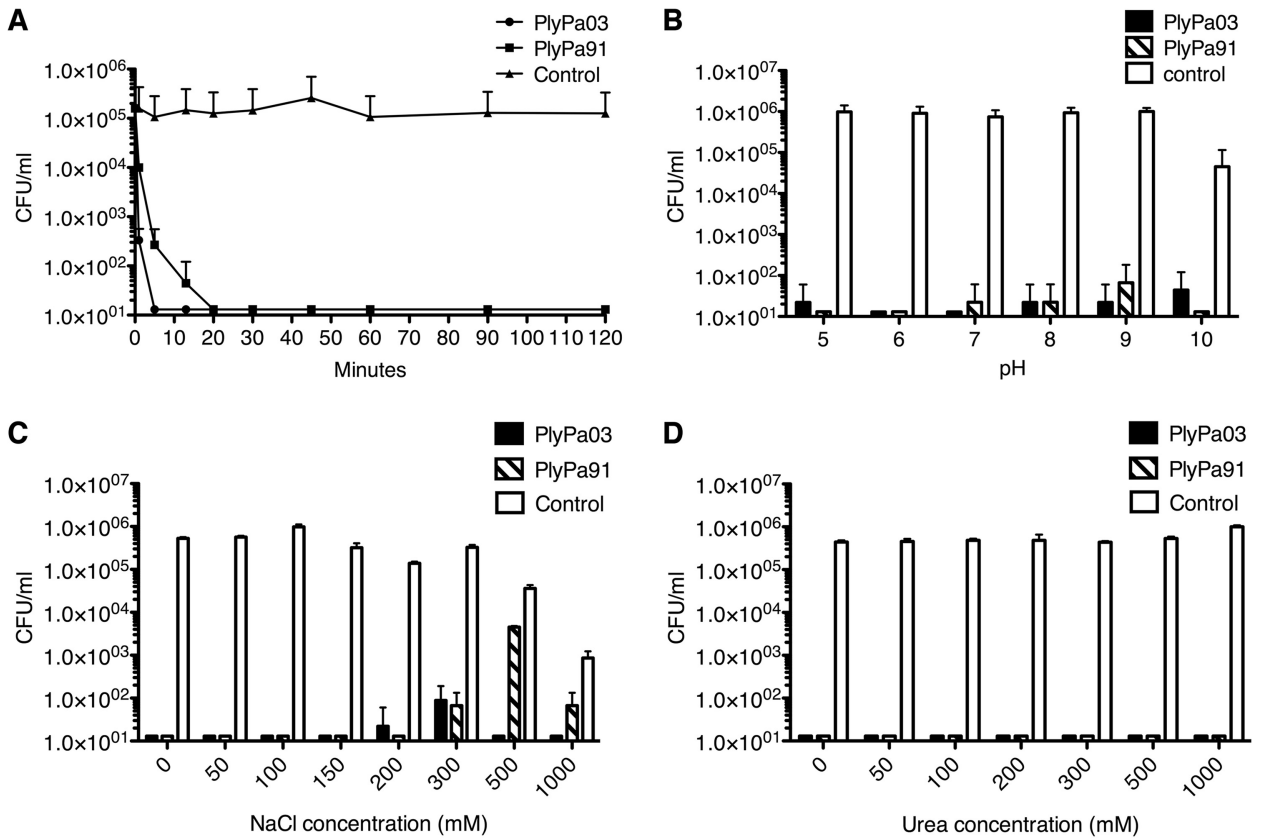

FIG 4 Characterization of PlyPa03 and PlyPa91. (A) Time-kill curve. Log-phase $P$. aeruginosa PAO1 cells were incubated for various lengths of time at $37^{\circ} \mathrm{C}$ with $100-\mu \mathrm{g} / \mathrm{ml}$ lysin in $30 \mathrm{mM}$ HEPES buffer. (B) Effect of pH. Log-phase $P$. aeruginosa PAO1 cells were incubated for $1 \mathrm{~h}$ at $37^{\circ} \mathrm{C}$ with $100-\mu \mathrm{g} / \mathrm{ml}$ lysin in $25 \mathrm{mM}$ the following buffers: pH 5.0, acetate buffer; pH 6.0, MES buffer; pH 7.0 and 8.0, HEPES buffer; pH 9.0, CHES buffer; pH 10.0, CAPS buffer. (C) Effect of $\mathrm{NaCl}$. Log-phase P. aeruginosa PAO1 cells were incubated with $100-\mu \mathrm{g} / \mathrm{ml} \mathrm{PlyPa03} \mathrm{or} \mathrm{PlyPa91}$ for $1 \mathrm{~h}$ at $37^{\circ} \mathrm{C}$ in $30 \mathrm{mM}$ HEPES, $\mathrm{pH} 7.4$, and various concentrations of $\mathrm{NaCl}$. (D) Effect of urea. Log-phase $P$. aeruginosa PAO1 cells were incubated with $100-\mu \mathrm{g} / \mathrm{ml}$ PlyPa03 or PlyPa91 for $1 \mathrm{~h}$ at $37^{\circ} \mathrm{C}$ in $30 \mathrm{mM} \mathrm{HEPES,} \mathrm{pH} 7.4$, and various concentrations of urea. In all cases, the surviving bacteria were enumerated by serial dilution and plating. Experiments were done in triplicate; error bars represent standard deviations.

We then tested the lysins against other Gram-negative pathogens. PlyPa03 and PlyPa91 had good killing activity against most Klebsiella and Enterobacter strains tested, resulting in 5-log kill in most cases, while PlyPa01 and PlyPa96 displayed only weak to moderate killing activity (Fig. 3B). PlyPa03 displayed relatively weak activity against $E$. coli, Shigella flexneri, and Citrobacter freundii, but PlyPa91 was active against these species, demonstrating a broader activity range (Fig. $3 C$ ). All enzymes had good activity against $A$. baumannii and Shigella sonnei but only moderate to weak activity against Salmonella spp. and Proteus mirabilis. None of the enzymes had substantial activity against Serratia marcescens and the Gram-positive bacteria Staphylococcus aureus and Bacillus anthracis. These results revealed that despite the relatively broad range of activity of the lysins tested, some level of species specificity does exist. Based on these results, we chose to proceed with $\mathrm{PlyPa03}$ and $\mathrm{PlyPa} 91$ in further experiments.

Characterization of PlyPa03 and PlyPa91. To evaluate the relative rate of $P$. aeruginosa killing by PlyPa03 and PlyPa91, we incubated $P$. aeruginosa PAO1 cells with these lysins from $1 \mathrm{~min}$ to $2 \mathrm{~h}$ using them at $100 \mu \mathrm{g} / \mathrm{ml}$ each (Fig. 4A). PlyPa03 rapidly killed $P$. aeruginosa, resulting in a $>2$-log kill after $1 \mathrm{~min}$ and a reduction to below the detection level after 5 min. PlyPa91 had slightly slower killing kinetics, resulting in a 1-log kill after $1 \mathrm{~min},>2$-log kill after $5 \mathrm{~min}$, and a reduction to below the detection level after $20 \mathrm{~min}$.

We next characterized the effect of $\mathrm{pH}$ on the activity of PlyPa03 and PlyPa91. Log-phase $P$. aeruginosa cells were incubated with each of the lysins under buffer conditions ranging from $\mathrm{pH} 5.0$ to 10.0 (Fig. 4B). Both PlyPa03 and PlyPa91 effectively killed $P$. aeruginosa under all $\mathrm{pH}$ conditions tested. We further explored more subtle differences in activity at $\mathrm{pH} 6.0$ to 9.0 by performing the experiments at various lysin concentrations (Fig. S8). Only slight differences in activity were observed among the different $\mathrm{pH}$ conditions, with $\mathrm{PlyPa03}$ showing somewhat better activity at $\mathrm{pH} 6.0$ and 


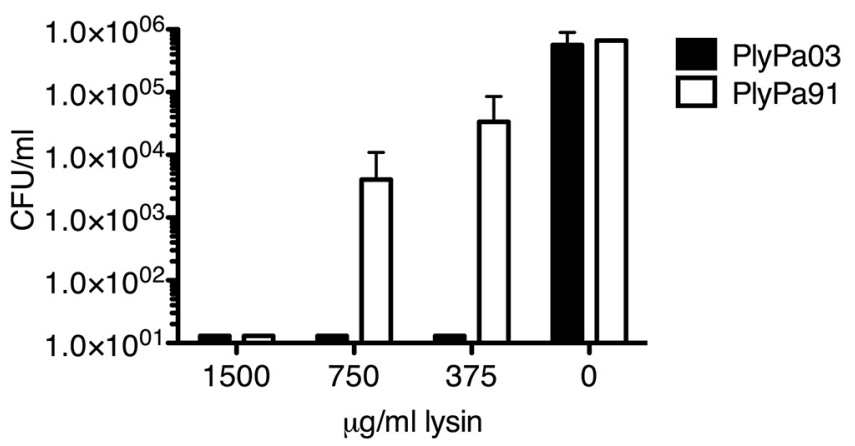

FIG 5 Elimination of $P$. aeruginosa biofilm by PlyPa03 and PlyPa91. A P. aeruginosa PAO1 biofilm was established using the MBEC biofilm inoculator 96-well plate system. Biofilms were grown for $24 \mathrm{~h}$ on the 96-peg lid, washed twice, and treated with different concentrations of PlyPa03, PlyPa91, or the buffer control for $2 \mathrm{~h}$ at $37^{\circ} \mathrm{C}$. The pegs were washed, and the surviving bacteria were recovered by sonication in $200 \mu \mathrm{l} /$ well PBS. Quantification of the surviving bacteria was done by serial dilution and plating. Experiments were done in triplicate; error bars represent standard deviations.

7.0 than at $\mathrm{pH} 8.0$ and 9.0 and with PlyPa91 showing somewhat better activity at $\mathrm{pH} 6.0$ and 9.0 than at $\mathrm{pH} 7.0$ and 8.0 (Fig. S8).

We next evaluated the effect of salt on the activity of PlyPa03 and PlyPa91 (Fig. 4C). In control samples, bacterial viability remained relatively constant up to $300 \mathrm{mM} \mathrm{NaCl}$ but was slightly reduced at $500 \mathrm{mM} \mathrm{NaCl}$ and substantially reduced at $1 \mathrm{M} \mathrm{NaCl}$ (preventing the reliable estimation of lysin activity at this concentration). PlyPa03 remained active in $\mathrm{NaCl}$ concentrations as high as $500 \mathrm{mM}$; however, the activity of PlyPa91 was substantially inhibited at $500 \mathrm{mM} \mathrm{NaCl}$. We also evaluated the activity of $\mathrm{PlyPa03}$ and PlyPa91 in urea. Both lysins were fully active in all urea concentrations tested up to $1 \mathrm{M}$. No reduction in bacterial viability was seen at these urea concentrations in the absence of lysins (Fig. 4D).

Chelation of divalent cations by EDTA destabilizes the outer membrane of Gramnegative bacteria and can thus promote the translocation of externally applied lysins into the periplasm, where they can degrade the cell wall peptidoglycan $(20,30)$. We incubated $P$. aeruginosa cells with serially diluted PlyPa03 and PlyPa91 in the presence or absence of $0.5 \mathrm{mM}$ EDTA and determined the effect on killing activity (Fig. S9). Only a slight improvement in killing was observed for PlyPa03 in the presence of EDTA (at $5 \mu \mathrm{g} / \mathrm{ml}$ ), and no improvement in killing was observed for PlyPa91. This may indicate that permeabilization of the outer membrane through chelation of divalent cations is not necessary for the activity of these lysins.

Lysin activity against Pseudomonas biofilm and in serum and surfactant. To test the effect of PlyPa03 and PlyPa91 on P. aeruginosa biofilm, we used the MBEC biofilm inoculator 96-well plate system. Biofilms were grown for $24 \mathrm{~h}$ on the 96-peg lid, washed, and treated with different concentrations of PlyPa03, PlyPa91, or the buffer control for $2 \mathrm{~h}$ at $37^{\circ} \mathrm{C}$. The bacteria remaining on the pegs were dissociated by sonication and quantified by serial dilutions and plating. PlyPa03 completely eliminated $P$. aeruginosa biofilms at all concentrations tested down to $0.375 \mathrm{mg} / \mathrm{ml}$. Treatment with PlyPa91 resulted in a $>1$-log CFU drop at $0.375 \mathrm{mg} / \mathrm{ml}$, a $>2$-log CFU drop at $0.75 \mathrm{mg} / \mathrm{ml}$, and complete elimination of the biofilm at $1.5 \mathrm{mg} / \mathrm{ml}$ (Fig. 5). Thus, while both enzymes were effective in the elimination of the $P$. aeruginosa biofilm, PlyPa03 performed substantially better.

Next, we tested the activity of the lysins against $P$. aeruginosa in the presence of human serum (Fig. 6A). A very small amount of serum (1\%) completely inhibited the killing activity of PlyPa03. On the other hand, PlyPa91 retained some activity at low serum concentrations, but it, too, was completely inhibited at $8 \%$ serum. As such, these lysins are not suitable for systemic use and would be better suited for topical applications. Nevertheless, PlyPa91 may be a better choice in topical environments, where a certain amount of serum components may be expected. 

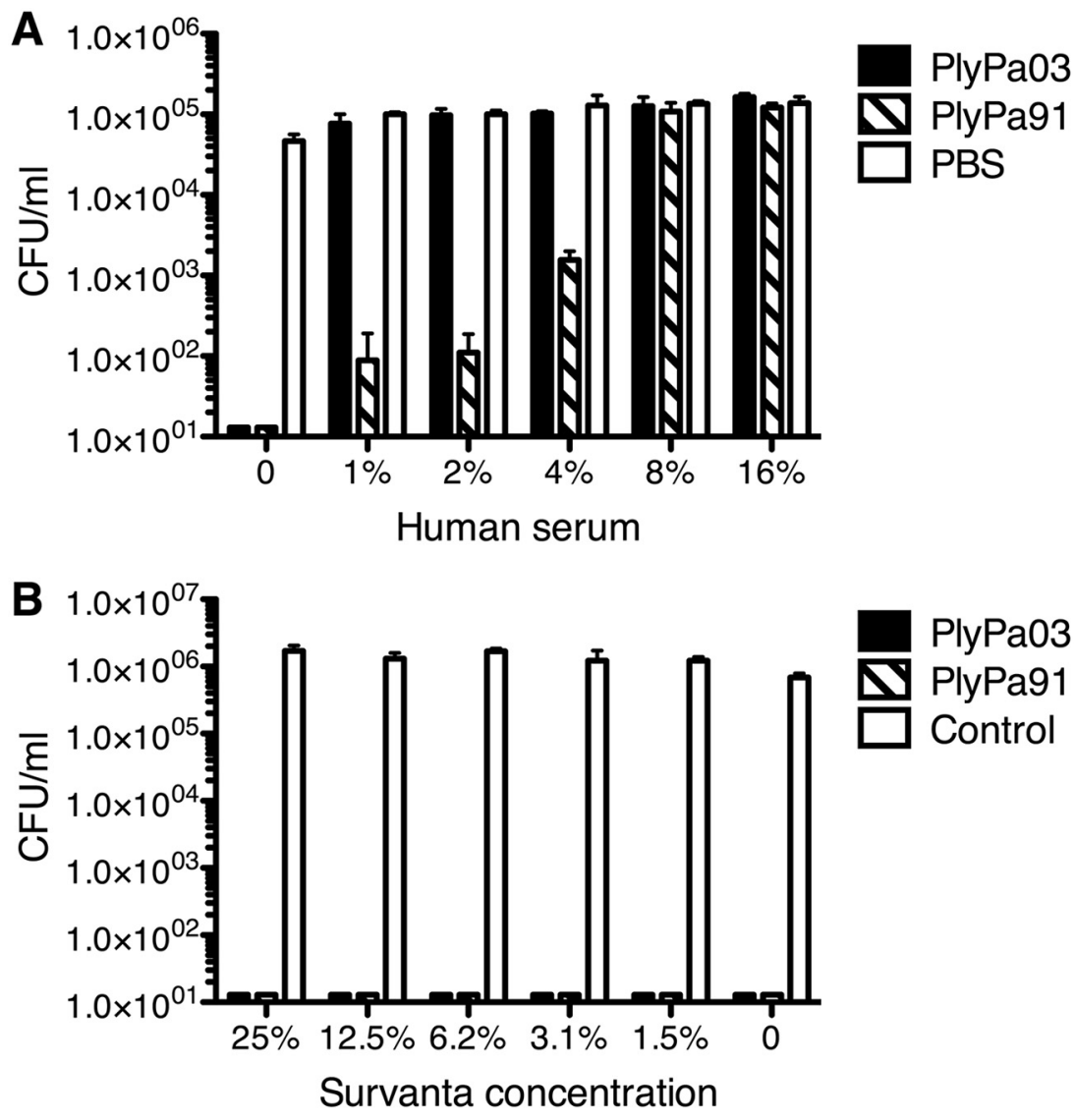

FIG 6 Activity of PlyPa03 and PlyPa91 in the presence of human serum and beractant (Servanta). Log-phase $P$. aeruginosa PAO1 cells were incubated for $1 \mathrm{~h}$ at $37^{\circ} \mathrm{C}$ with $100 \mu \mathrm{g} / \mathrm{ml}$ of PlyPa03, PlyPa91, or the buffer control in the presence of the indicated concentration of serum (A) or beractant (B). The numbers of viable bacterial CFU were determined by serial dilution and plating. Experiments were done in triplicate; error bars represent standard deviations.

An important potential use for lysins directed against $P$. aeruginosa is in the treatment of pneumonia. P. aeruginosa is among the most common causes of nosocomial pneumonia, an infection with a mortality rate as high as $30 \%$ (31). Lung surfactants are prominent components of the alveolar mucosa and are critical for the maintenance of proper surface tension in the alveoli (32). Beractant is a concentrated mixture of bovine lung surfactants and artificial surfactants and as such could be used to approximate the effect of lung surfactant on lysin activity. PlyPa03 and PlyPa91 were fully active against $P$. aeruginosa in the presence of all beractant concentrations tested up to $25 \%$ (Fig. 6B).

Evaluation of cytotoxic effects of the lysins. To evaluate the cytotoxicity of PlyPa03 and PlyPa91, we first determined their effect on human red blood cells (RBCs). Human RBCs were incubated with PlyPa03 and PlyPa91 at concentrations ranging from 1 to $200 \mu \mathrm{g} / \mathrm{ml}$ for $4 \mathrm{~h}$, and the release of hemoglobin was evaluated following the removal of intact cells. No lysis of cells was observed at any concentration of either PlyPa03 or PlyPa91, while the positive control, $1 \%$ Triton $\mathrm{X}-100$, resulted in the appreciable release of hemoglobin from the cells (Fig. 7A). Thus, these lysins do not appear to have a lytic effect on RBC membranes.

Next, we determined the cytotoxic effects of lysins on HL-60 neutrophils using the CellTiter 96 nonradioactive cell proliferation assay. HL-60 cells were incubated with various concentrations of lysins for $4 \mathrm{~h}$, and cell viability was evaluated based on the ability of live cells to convert tetrazolium into a formazan product. The positive control (1\% Triton $\mathrm{X}-100)$ resulted in a marked decrease in cellular viability, while lysins at all concentrations tested resulted in viability values comparable to those achieved with 

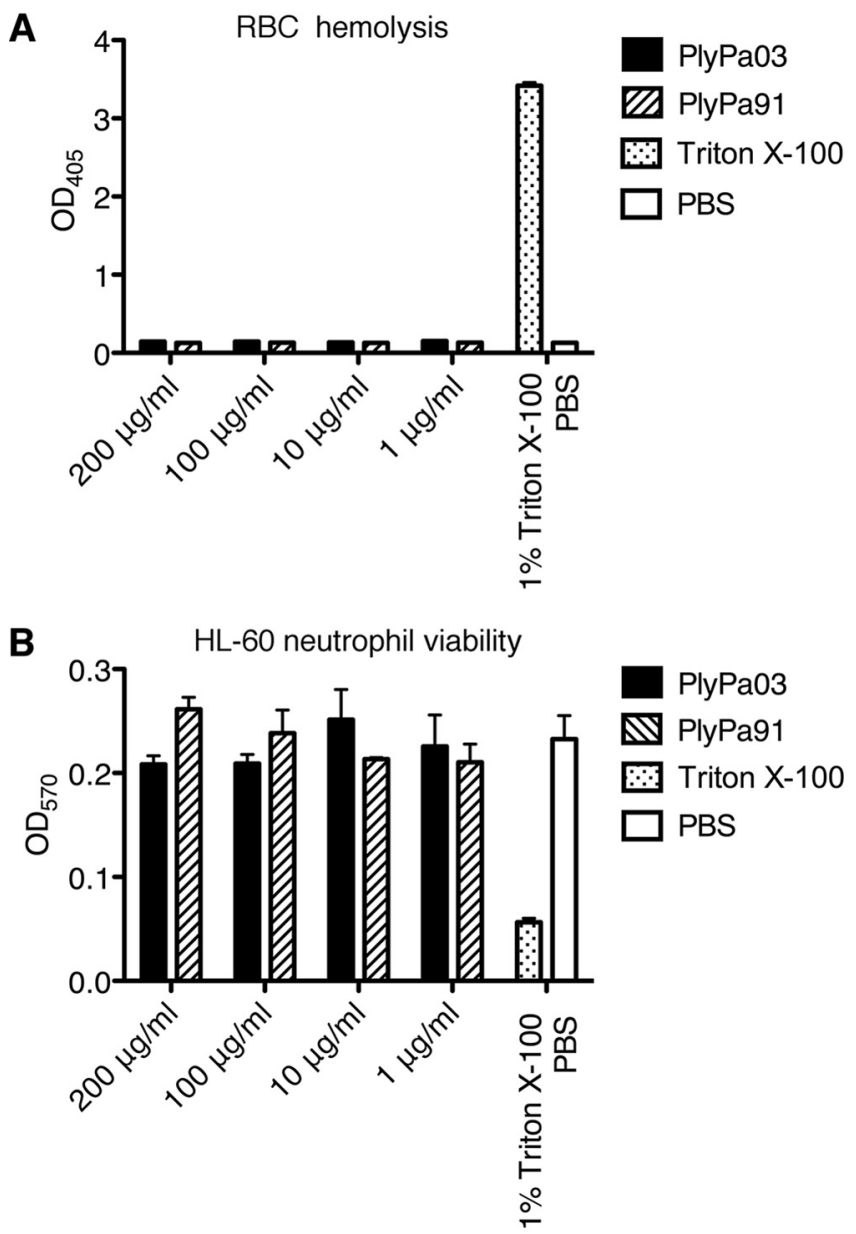

FIG 7 PlyPa03 and PlyPa91 are not cytotoxic to human cells. (A) Human red blood cells from healthy donors were suspended in PBS and incubated with PlyPa03 or PlyPa91 at concentrations ranging from 1 to $200 \mu \mathrm{g} / \mathrm{ml}$ for $4 \mathrm{~h}$ at $37^{\circ} \mathrm{C}$. PBS was used as a negative control, and $1 \%$ Triton X-100 was used as a positive control. Hemoglobin release was evaluated by measuring the absorbance at $405 \mathrm{~nm}$ following the removal of intact cells. (B) HL-60 neutrophils were incubated with HBSS containing various concentrations of PlyPa03 or PlyPa91 in a 96 -well plate for $4 \mathrm{~h}$ at $37^{\circ} \mathrm{C}$ in $5 \% \mathrm{CO}_{2}$. Tetrazolium substrate was added for $4 \mathrm{~h}$, and stop solution was added overnight. The absorbance was measured at $\mathrm{OD}_{570}$ to evaluate the conversion of tetrazolium into a formazan product by live cells. Triton X-100 (1\%) served as a positive control, and PBS served as a negative control. Assays were carried out in triplicate; error bars represent standard deviations.

the phosphate-buffered saline (PBS) negative control, demonstrating no signs of cytotoxicity (Fig. 7B).

Evaluation of lysin efficacy in murine skin and lung models of infection. We next tested PlyPa03 in a mouse model of skin infection (33). Mice were shaved and depilated, and the top layers of the epidermis were removed by tape stripping 15 to 20 times. $P$. aeruginosa cells were applied to the skin and allowed to establish infection for $20 \mathrm{~h}$. The infected skin was treated with a single $200-\mu \mathrm{g}$ or $300-\mu \mathrm{g}$ dose of PlyPa03 or the buffer control. Three hours later, the mice were euthanized, the infected skin was excised and homogenized, and the bacterial burden was evaluated by serial dilution and plating. Treatment of the infected skin with $\mathrm{PlyPa03}$ resulted in a dose-dependent reduction in the $P$. aeruginosa load, with the $300-\mu \mathrm{g}$ dose leading to $>2$-log mean reduction in the bacterial load (Fig. $8 \mathrm{~A}$ ). In a follow-up experiment we repeated the treatment with the single $300-\mu \mathrm{g}$ dose of $\mathrm{PlyPaO}$ and included an additional group of mice treated with $100 \mu \mathrm{g}$ PlyPa91. The results for the PlyPa03-treated group were in line with those of the previous experiment, resulting in a $>2$-log mean reduction in the bacterial load, while $100 \mu \mathrm{g}$ PlyPa91 resulted in a 1-log reduction in bacterial counts 
A

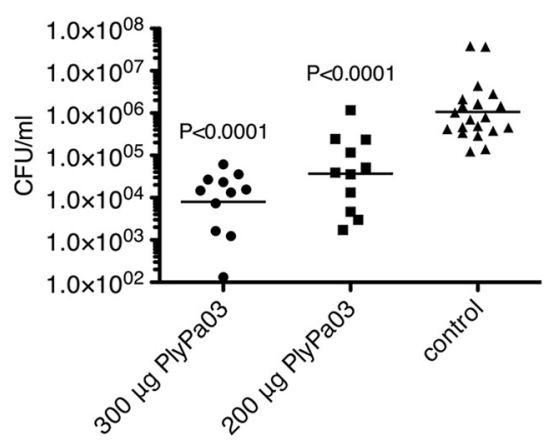

C -.. PlyPa91 nasal \& lung delivery $\mathrm{N}=20$

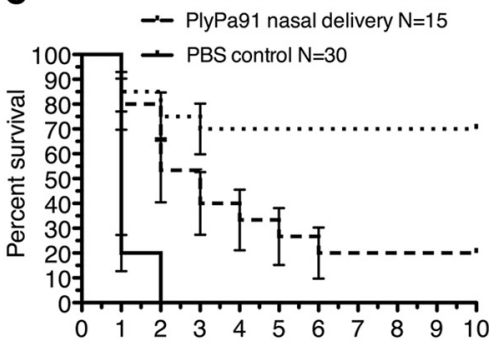

Days Elapsed

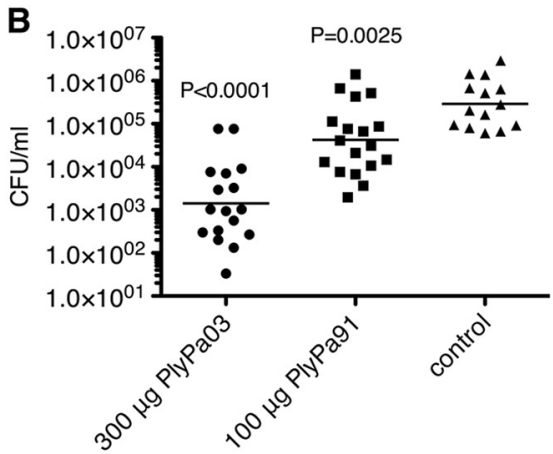

FIG 8 Evaluation of PlyPa03 and PlyPa91 in murine skin and lung infection models. (A) A skin area on the backs of CD1 female mice was shaved, tape stripped, and then infected with $10 \mu$ l log-phase $P$. aeruginosa bacteria at $5 \times 10^{6} \mathrm{CFU} / \mathrm{ml}$. After $20 \mathrm{~h}$, the mice were treated with $300 \mu \mathrm{g}$ or $200 \mu \mathrm{g}$ PlyPa03 or the buffer control and were euthanized $3 \mathrm{~h}$ later. The infected skin was immediately excised and homogenized in PBS, and the resulting liquid was serially diluted and plated for CFU quantification. The geometric means of the values are presented. (B) The skin infection model was performed as described in the legend to panel $A$, and mice were treated with $300 \mu \mathrm{g} P l y P a 03,100 \mu \mathrm{g}$ PlyPa91, or the buffer control. The values on the $y$ axes of panels $A$ and $B$ are the numbers of CFU per milliliter. (C) The lungs of female C57BL/ 6 mice were infected by intranasal application twice of $50 \mu \mathrm{l}$ of $10^{8} \mathrm{CFU} / \mathrm{ml}$ of log-phase $P$. aeruginosa PAO1 bacteria by intranasal instillation. At 3 and $6 \mathrm{~h}$ postinfection, the mice were treated with $50 \mu \mathrm{l}$ of $1.8-\mathrm{mg} / \mathrm{ml}$ PlyPa91 or PBS by two intranasal instillations (nasal delivery) or by one intranasal and one intratracheal instillation (nasal and lung delivery); PBS controls from the two treatment regimens were combined in a single group. Ten-day survival was analyzed using Kaplan-Meier survival curves with standard errors, 95\% confidence intervals, and significance levels (log-rank/Mantel-Cox test). The results presented were combined from three separate experiments.

(Fig. 8B). Given that the reduction in bacterial counts was reproducible and dose dependent, it is expected that higher doses and multiple repeat doses could lead to increased efficacy.

We next sought to evaluate the efficacy of lysins in the treatment of $P$. aeruginosa pneumonia in a murine infection model. We chose to use PlyPa91 for these experiments, given its higher resistance to serum components, some of which may be present in the lung mucosal exudate during infection. Female C57BL/6 mice were infected by intranasal application twice of $50 \mu \mathrm{l}$ of $10^{8} \mathrm{CFU} / \mathrm{ml}$ of log-phase $P$. aeruginosa PAO1 to establish lung infection. The mice were treated at 3 and $6 \mathrm{~h}$ postinfection with $50 \mu \mathrm{l}$ of $1.8-\mathrm{mg} / \mathrm{ml}$ PlyPa91 in PBS or PBS alone either by two intranasal instillations or by one intranasal and one intratracheal instillation. The survival of the mice was monitored daily for 10 days (Fig. 8C). The majority of the mice in the control group died within the first $24 \mathrm{~h}$, and the remaining mice died by $48 \mathrm{~h}$ following infection. Mice treated with PlyPa91 in two intranasal instillations displayed a significant delay in death, with $20 \%$ of the mice surviving at day 10 . Mice treated by one intranasal and one intratracheal instillation displayed a further reduction in the death rate, with $70 \%$ of the mice surviving at day 10 (Fig. 8C). Thus, PlyPa91 displayed significant protection of the mice in this model, and the route of delivery was important for treatment efficacy. 


\section{DISCUSSION}

Bacteriophages have coevolved with bacteria for a billion years and through this process have developed efficient strategies to lyse and thus kill their bacterial host at the end of the infectious cycle for progeny release. We and others have taken advantage of the lysins used in this lytic process for the development of antibacterial therapeutics (34). Lysins kill bacteria by degrading the peptidoglycan mesh of the cell wall, resulting in osmotic lysis. In Gram-positive bacteria, the peptidoglycan target is exposed on the surface and is thus accessible to externally applied lysins; however, in Gram-negative organisms, the outer membrane prevents most externally applied lysins from reaching their peptidoglycan target. In this study, we exploited the large number of available $P$. aeruginosa sequenced genomes to identify lysins in their lysogenized phages with innate killing activity against $P$. aeruginosa. We used the sequence of a highly effective A. baumannii lysin, PlyF307 (27), as a starting point for a BLAST analysis of Pseudomonas genomes, yielding over 100 hits. Through phylogenetic analysis and successive rounds of lysin expression and characterization, we identified two lysins that were highly active against $P$. aeruginosa. These lysins, PlyPa03 and PlyPa91, were effective against log-phase and stationary bacteria and were able to kill a wide range of Gram-negative organisms, including clinical isolates of $P$. aeruginosa, A. baumannii, K. pneumoniae, and Enterobacter cloacae. The lysins were active in a broad pH range, in high urea concentrations, and in the presence of lung surfactants (beractant) and did not display toxicity against human cells.

Each of the lysins had a set of specific advantages. PlyPa03 was easier to produce in large quantities and displayed a potent killing activity, leading to a $>5$-log-CFU reduction within $5 \mathrm{~min}$, whereas PlyPa91 required $20 \mathrm{~min}$ to achieve this level of reduction. Additionally, PlyPa03 was more resistant to salt, remaining active at $500 \mathrm{mM}$ $\mathrm{NaCl}$, while PlyPa91 was active only up to $300 \mathrm{mM} \mathrm{NaCl}$ (still well above the physiological salt concentration). PlyPa03 was also more effective against biofilms, an important trait given the role that biofilms play in $P$. aeruginosa colonization and infection of the human host. Despite these advantages, $\mathrm{PlyPa03}$ was highly sensitive to human serum, losing activity even in the presence of 1\% serum, while PlyPa91 retained activity in low serum concentrations (up to $4 \%$ ). Thus, while neither enzyme could be used systemically, PlyPa91 may be better suited for use in environments where a small amount of serum components may be present. In a mouse model of $P$. aeruginosa skin infection, PlyPa03 demonstrated significant (>2-log kill) and dose-dependent killing of $P$. aeruginosa, showing potential in the treatment of topical $P$. aeruginosa infections. PlyPa91 was tested only at the $100-\mu \mathrm{g}$ dose due to limitations in the amount of concentrated lysin available, resulting in over 1-log kill. We chose PlyPa91 for use in the murine pneumonia model, reasoning that it may be better suited for use in infected mucosal environments, based on its higher resistance to serum components. In this model, PlyPa91 protected mice from death following $P$. aeruginosa delivery to the lungs. Importantly, the route of delivery had a significant effect on the survival of the mice. Whereas $70 \%$ of mice treated with a combination of intranasal and intratracheal instillations were protected, only $20 \%$ of mice treated with two intranasal instillations survived, even though a similar amount of lysin was used. Thus, in a clinical setting, an effective delivery system combined with repeated dosing could greatly contribute to treatment efficacy.

There is a clear unmet need for the treatment of MDR $P$. aeruginosa colonization and infections in topical and mucosal environments. $P$. aeruginosa is the second most commonly isolated organism from patients with ventilator-associated pneumonia (VAP) (35), an infection that has a mortality rate as high as $30 \%$ (31). P. aeruginosa is also a common infecting pathogen in topical settings, including burn wounds (6), acute otitis externa (swimmer's ear) (36), and ulcerative keratitis (37). Lysins have several advantages compared with traditional antibiotics. They kill bacteria faster than antibiotics, and resistance to lysins is a rare event due to the conserved nature of their peptidoglycan target. Resistance has not been observed for lysins targeting Gram-positive bacteria 
$(15,17)$ or for the Gram-negative bacterial Artilysin Art-175 when tested against $P$. aeruginosa and $A$. baumannii $(38,39)$. Because of their broad activity against Klebsiella and Enterobacter strains, in addition to $P$. aeruginosa, the enzymes described in this study hold promise as new agents to control a range of topical and mucosal MDR Gram-negative bacterial infections.

\section{MATERIALS AND METHODS}

Ethics statement. Samples from human subjects were obtained in accordance with protocol VFI-0790, approved by The Rockefeller University Institutional Review Board, and all subjects gave informed consent. Mouse work was performed in accordance with protocol number $14691 \mathrm{H}$, approved by The Rockefeller University's Institutional Animal Care and Use Committee. All experiments were conducted at The Rockefeller University's animal housing facility, an AAALAC-accredited research facility, with all efforts being made to minimize suffering.

Bactericidal assays. An overnight culture of the test bacteria was diluted 1:50 into fresh LB medium and grown to an optical density at $600 \mathrm{~nm}\left(\mathrm{OD}_{600}\right)$ of 0.5 . The cells were harvested, washed, and suspended in $30 \mathrm{mM}$ HEPES buffer, pH 7.4, to a final concentration of about $10^{6}$ cell $\mathrm{s} / \mathrm{ml}$ (unless otherwise noted). In a U-bottomed 96-well plate, each lysin was diluted to the desired final concentration in $50 \mu \mathrm{l}$ $30 \mathrm{mM}$ HEPES buffer, and then $50 \mu \mathrm{l}$ of the test bacteria was added to each well. The plate was incubated for $1 \mathrm{~h}$ at $37^{\circ} \mathrm{C}$ with shaking at $200 \mathrm{rpm}$. The content of each well was then serially diluted 10 -fold and streaked on LB plates to quantify viable bacteria. Mueller-Hinton agar plates were used in experiments with Gram-positive bacteria.

For time-kill curves, following incubation, assay contents were diluted 1:1 in 5\% BBL beef extract (BD) to stop the reaction and were immediately diluted and plated. Assays evaluating the effect of $\mathrm{pH}$ were done by adding $25 \mu \mathrm{l}$ of $100 \mathrm{mM}$ the following buffers to wells of a 96-well plate (final concentration, $25 \mathrm{mM}$ ): pH 5.0, acetate buffer; pH 6.0, MES (morpholineethanesulfonic acid) buffer; pH 7.0 and 8.0, HEPES buffer; pH 9.0, N-cyclohexyl-2-aminoethanesulfonic acid (CHES) buffer; pH 10.0, N-cyclohexyl-3aminopropanesulfonic acid (CAPS) buffer. Bacteria and lysins were diluted in deionized water rather than buffer as not to affect the final $\mathrm{pH}$ of the reaction mixtures. Assays evaluating the effect of salt and urea were carried out in $30 \mathrm{mM}$ HEPES buffer, $\mathrm{pH} 7.4,100-\mu \mathrm{g} / \mathrm{ml}$ lysins. Evaluation of the effect of serum was done in $30 \mathrm{mM}$ HEPES buffer, $\mathrm{pH} 7.4,100-\mu \mathrm{g} / \mathrm{ml}$ lysins, using serially diluted pooled human type $A B$ blood serum from male subjects (Sigma). Experiments in beractant (Survanta; Abbvie) were carried out in $30 \mathrm{mM}$ HEPES buffer, $\mathrm{pH} 7.4$, and $100-\mu \mathrm{g} / \mathrm{ml}$ lysins. Kill assays were done in duplicate or triplicate and repeated at least twice.

Biofilm assays. An overnight culture of $P$. aeruginosa PAO1 was diluted 1:1,000 in tryptic soy broth containing $0.2 \%$ glucose. The diluted bacteria were added to an MBEC biofilm inoculator 96 -well plate (catalog number 9111 ; Innovotech) at $100 \mu \mathrm{l} /$ well and placed in a plastic bag with a wet paper towel to maintain humidity. The biofilm was grown at $37^{\circ} \mathrm{C}$ for $24 \mathrm{~h}$ at $65 \mathrm{rpm}$. The 96 -peg lid, which contained established biofilm, was removed and washed twice using 96-well plates with $200 \mu \mathrm{l} /$ well PBS. The washed biofilm was then transferred to a 96-well plate containing $200 \mu \mathrm{l} /$ well of the lysins or controls and placed in a $37^{\circ} \mathrm{C}$ shaker at $65 \mathrm{rpm}$ for $2 \mathrm{~h}$. The biofilms were then washed with PBS as described above and transferred to a 96-well plate containing $200 \mu \mathrm{l} /$ well PBS for recovery by water bath sonication for $30 \mathrm{~min}$. Quantification of surviving cells was done by serial dilutions and plating.

Cytotoxicity assay. Hemolysis of human red blood cells (RBCs) was evaluated using blood from healthy volunteers at The Rockefeller University Hospital. Blood was collected in tubes containing EDTA, and RBCs were harvested by a low-speed centrifugation at $800 \times g$ for $10 \mathrm{~min}$. The cells were washed three times with PBS and resuspended in $10 \%$ of the volume of PBS. In a 96-well microtiter plate, $100 \mu \mathrm{l}$ of the human RBC suspension was mixed 1:1 with PlyPa03 or PlyPa91 to yield final concentrations ranging from 1 to $200 \mu \mathrm{g} / \mathrm{ml}$. PBS and $1 \%$ Triton X-100 were used as negative and positive controls, respectively. The 96 -well microtiter plate was then incubated for $4 \mathrm{~h}$ at $37^{\circ} \mathrm{C}$ in $5 \% \mathrm{CO}_{2}$. The intact $\mathrm{RBCs}$ were sedimented by low-speed centrifugation, and $100 \mu$ l of the supernatant was transferred into a new microtiter plate. The absorbance at $\mathrm{OD}_{405}$ was measured using a SpectraMax M5 microplate reader (Molecular Devices) to quantify the release of hemoglobin.

The cytotoxic effects of lysins on HL-60 neutrophils were evaluated using a CellTiter 96 nonradioactive cell proliferation assay (Promega). The HL-60 cell line was obtained from ATCC (ATCC CCL-240) and propagated in RPMI 1640 (Gibco, Life Technologies) containing GlutaMAX supplement (Gibco, Life Technologies) and 10\% heat-inactivated fetal bovine serum (GE Healthcare). The cells were harvested at 1,500 rpm for $5 \mathrm{~min}$, washed one time with Hanks' balanced salt solution (HBSS; Gibco), and then resuspended to $2 \times 10^{6}$ viable cells $/ \mathrm{ml}$ in HBSS. In a 96-well microtiter plate, $1 \times 10^{5} \mathrm{HL}-60$ cells were mixed with a final concentation of 1 to $200 \mu \mathrm{g} / \mathrm{ml}$ of PlyPa03 or PlyPa91 in triplicate. PBS and 1\% Triton $\mathrm{X}-100$ were used as negative and positive controls, respectively. The microtiter plate was incubated for $4 \mathrm{~h}$ at $37^{\circ} \mathrm{C}$ with $5 \% \mathrm{CO}_{2}$, dye solution was added to each sample, and the plate was incubated for 4 additional hours at $37^{\circ} \mathrm{C}$ with $5 \% \mathrm{CO}_{2}$. Stop solution was then added to each well, and the plate was incubated overnight at $37^{\circ} \mathrm{C}$. Viability was evaluated based on the ability of the cells to convert tetrazolium into a formazan product by measuring the absorbance at $\mathrm{OD}_{570}$ using a SpectraMax $\mathrm{M} 5$ microplate reader (Molecular Devices).

Mouse skin infection model. The skin infection model was based on the work of Pastagia et al. (33). Female CD1 mice, 6 to 8 weeks old (Charles River Laboratories, Wilmington, MA), were anesthetized by an intraperitoneal injection of ketamine $(1.2 \mathrm{mg} /$ animal $)$ and xylazine $(0.25 \mathrm{mg} / \mathrm{animal})$. The back of the mice was shaved with an electric razor and treated with depilatory cream to remove the remaining hair. 
Then, an area of $2 \mathrm{~cm}^{2}$ was tape stripped 15 to 20 times using autoclave tape (using a fresh piece of tape each time); two experimental areas were prepared for each mouse, and these were treated in a similar manner (treatment or control) to prevent cross contamination. The tape-stripped areas were then sanitized using alcohol wipes, allowed to dry for a few minutes, and then inoculated with $10 \mu \mathrm{l}$ of log-phase P. aeruginosa PAO1 at a concentration of $5 \times 10^{6} / \mathrm{ml}$. Infection was allowed to establish for $20 \mathrm{~h}$, and the mice were then treated with two sequential $25-\mu \mathrm{l}$ doses of lysin in CAPS-buffered saline, $\mathrm{pH}$ 6.0, or buffer control. At $3 \mathrm{~h}$ following treatment, the mice were euthanized and the wound area was excised. Each skin sample was homogenized in $500 \mu \mathrm{l}$ PBS using a Stomacher 80 Biomaster machine (Seward Ltd., United Kingdom). The homogenate was serially diluted and plated on LB plates supplemented with $100 \mu \mathrm{g} / \mathrm{ml}$ ampicillin as a selective agent to prevent the growth of normal skin flora ( $P$. aeruginosa is resistant to ampicillin), in order to calculate the number of $P$. aeruginosa CFU in the skin sample.

Mouse lung infection model. Female C57BL/6 mice, 9 to 10 weeks old (Charles River Laboratories, Wilmington, MA), were anesthetized using isoflurane. Lung infection was established by intranasal instillation twice of $50 \mu \mathrm{l}$ of $10^{8} \mathrm{CFU} / \mathrm{ml}$ of log-phase $P$. aeruginosa PAO1. To determine the bacterial load in the lungs before treatment, 2 animals were euthanized $3 \mathrm{~h}$ after challenge, the lungs were divided into the top half and the bottom half and homogenized in $500 \mu \mathrm{l} \mathrm{PBS}$, and the CFU counts were determined. The mean count in both the upper and the lower halves was about $10^{6} \mathrm{CFU} / \mathrm{ml}$. The mice were treated at 3 and $6 \mathrm{~h}$ postinfection with $50 \mu \mathrm{l}$ of $1.8-\mathrm{mg} / \mathrm{ml} \mathrm{PlyPa} 91$ or PBS by two intranasal instillations or by one intranasal and one intratracheal instillation. All treatments were performed on isoflurane-anesthetized mice. A $100-\mu l$ pipette and tips were used for intranasal application. Intratracheal instillation was performed as previously described (40). A 22-gauge catheter was inserted into the mouse trachea using a mouse fiberoptic endotracheal intubation kit from Kent Scientific Corp. Then, $50 \mu$ l of treatment liquid was added into the bottom of the catheter and injected into the lungs with $200 \mu \mathrm{l}$ of air from an attached $1-\mathrm{cm}^{3}$ syringe. The survival of the mice was monitored daily for 10 days.

Statistical analysis. A two-tailed Student's $t$ test was used to evaluate statistical significance in bactericidal assays, biofilm assays, and murine skin models. Data from the murine lung infection model were statistically analyzed using Kaplan-Meier survival curves with standard errors, 95\% confidence intervals, and significance levels (log-rank/Mantel-Cox test), calculated using the Prism (version 7) computer program (GraphPad Software, La Jolla, CA).

\section{SUPPLEMENTAL MATERIAL}

Supplemental material for this article may be found at https://doi.org/10.1128/AAC .00024-19.

SUPPLEMENTAL FILE 1, PDF file, 1.1 MB.

\section{ACKNOWLEDGMENTS}

We thank Tricia Alston, Tiffany Benjamin, Maggie Qiu, and Ryan Heselpoth for various contributions to this paper. We thank Lars Westblade of Weill Cornell Medical Center, New York, NY, and Eugene E. Gobern of NYU Hospital for providing us with contemporary clinical isolates and advice regarding clinical aspects of the study.

This study was supported in part with funds provided from ContraFect Corporation and The Rockefeller University.

\section{REFERENCES}

1. Silby MW, Winstanley C, Godfrey SA, Levy SB, Jackson RW. 2011. Pseudomonas genomes: diverse and adaptable. FEMS Microbiol Rev 35: 652-680. https://doi.org/10.1111/j.1574-6976.2011.00269.x.

2. Winstanley C, O'Brien S, Brockhurst MA. 2016. Pseudomonas aeruginosa evolutionary adaptation and diversification in cystic fibrosis chronic lung infections. Trends Microbiol 24:327-337. https://doi.org/10.1016/j.tim .2016.01.008.

3. Spencer RC. 1996. Predominant pathogens found in the European Prevalence of Infection in Intensive Care Study. Eur J Clin Microbiol Infect Dis 15:281-285. https://doi.org/10.1007/BF01695658.

4. Koulenti D, Lisboa T, Brun-Buisson C, Krueger W, Macor A, Sole-Violan J, Diaz E, Topeli A, DeWaele J, Carneiro A, Martin-Loeches I, Armaganidis A, Rello J, EU-VAP/CAP Study Group. 2009. Spectrum of practice in the diagnosis of nosocomial pneumonia in patients requiring mechanical ventilation in European intensive care units. Crit Care Med 37: 2360-2368. https://doi.org/10.1097/CCM.0b013e3181a037ac.

5. Livermore DM. 2002. Multiple mechanisms of antimicrobial resistance in Pseudomonas aeruginosa: our worst nightmare? Clin Infect Dis 34: 634-640. https://doi.org/10.1086/338782.

6. Lyczak JB, Cannon CL, Pier GB. 2000. Establishment of Pseudomonas aeruginosa infection: lessons from a versatile opportunist. Microbes Infect 2:1051-1060. https://doi.org/10.1016/S1286-4579(00)01259-4.
7. Kidd TJ, Ramsay KA, Hu H, Marks GB, Wainwright CE, Bye PT, Elkins MR, Robinson PJ, Rose BR, Wilson JW, Grimwood K, Bell SC, ACPinCF Investigator Group. 2013. Shared Pseudomonas aeruginosa genotypes are common in Australian cystic fibrosis centres. Eur Respir J 41:1091-1100. https://doi.org/10.1183/09031936.00060512.

8. Nicas TI, Hancock RE. 1983. Pseudomonas aeruginosa outer membrane permeability: isolation of a porin protein F-deficient mutant. J Bacteriol 153:281-285.

9. Hancock RE. 1998. Resistance mechanisms in Pseudomonas aeruginosa and other nonfermentative gram-negative bacteria. Clin Infect Dis 27(Suppl 1):S93-S99. https://doi.org/10.1086/514909.

10. El Solh AA, Alhajhusain A. 2009. Update on the treatment of Pseudomonas aeruginosa pneumonia. J Antimicrob Chemother 64:229-238. https://doi.org/10.1093/jac/dkp201.

11. Evans ME, Feola DJ, Rapp RP. 1999. Polymyxin B sulfate and colistin: old antibiotics for emerging multiresistant gram-negative bacteria. Ann Pharmacother 33:960-967. https://doi.org/10.1345/aph.18426.

12. Falagas ME, Rizos M, Bliziotis IA, Rellos K, Kasiakou SK, Michalopoulos A. 2005. Toxicity after prolonged (more than four weeks) administration of intravenous colistin. BMC Infect Dis 5:1. https://doi.org/10.1186/1471 $-2334-5-1$.

13. Li J, Nation RL, Turnidge JD, Milne RW, Coulthard K, Rayner CR, Paterson 
DL. 2006. Colistin: the re-emerging antibiotic for multidrug-resistant Gram-negative bacterial infections. Lancet Infect Dis 6:589-601. https:// doi.org/10.1016/S1473-3099(06)70580-1.

14. Young R. 2014. Phage lysis: three steps, three choices, one outcome. J Microbiol 52:243-258. https://doi.org/10.1007/s12275-014-4087-z.

15. Schuch R, Nelson D, Fischetti VA. 2002. A bacteriolytic agent that detects and kills Bacillus anthracis. Nature 418:884-889. https://doi.org/10.1038/ nature01026.

16. Fischetti VA. 2010. Bacteriophage endolysins: a novel anti-infective to control Gram-positive pathogens. Int J Med Microbiol 300:357-362. https://doi.org/10.1016/j.ijmm.2010.04.002.

17. Loeffler JM, Nelson D, Fischetti VA. 2001. Rapid killing of Streptococcus pneumoniae with a bacteriophage cell wall hydrolase. Science 294: 2170-2172. https://doi.org/10.1126/science.1066869.

18. Gilmer DB, Schmitz JE, Euler CW, Fischetti VA. 2013. Novel bacteriophage lysin with broad lytic activity protects against mixed infection by Streptococcus pyogenes and methicillin-resistant Staphylococcus aureus. Antimicrob Agents Chemother 57:2743-2750. https://doi.org/10.1128/AAC .02526-12.

19. Díez-Martínez R, de Paz HD, de Paz H, Bustamante N, García E, Menéndez M, García P. 2013. Improving the lethal effect of cpl-7, a pneumococcal phage lysozyme with broad bactericidal activity, by inverting the net charge of its cell wall-binding module. Antimicrob Agents Chemother 57:5355-5365. https://doi.org/10.1128/AAC.01372-13.

20. Walmagh M, Briers Y, dos Santos SB, Azeredo J, Lavigne R. 2012. Characterization of modular bacteriophage endolysins from Myoviridae phages OBP, 201phi2-1 and PVP-SE1. PLoS One 7:e36991. https://doi .org/10.1371/journal.pone.0036991.

21. Ibrahim HR, Yamada M, Matsushita K, Kobayashi K, Kato A. 1994. Enhanced bactericidal action of lysozyme to Escherichia coli by inserting a hydrophobic pentapeptide into its $C$ terminus. J Biol Chem 269:5059-5063.

22. Arima H, Ibrahim HR, Kinoshita T, Kato A. 1997. Bactericidal action of lysozymes attached with various sizes of hydrophobic peptides to the C-terminal using genetic modification. FEBS Lett 415:114-118. https:// doi.org/10.1016/S0014-5793(97)01071-5.

23. Morita M, Tanji Y, Orito Y, Mizoguchi K, Soejima A, Unno H. 2001. Functional analysis of antibacterial activity of Bacillus amyloliquefaciens phage endolysin against Gram-negative bacteria. FEBS Lett 500:56-59. https://doi.org/10.1016/S0014-5793(01)02587-X.

24. Orito Y, Morita M, Hori K, Unno H, Tanji Y. 2004. Bacillus amyloliquefaciens phage endolysin can enhance permeability of Pseudomonas aeruginosa outer membrane and induce cell lysis. Appl Microbiol Biotechnol 65:105-109. https://doi.org/10.1007/s00253-003-1522-1.

25. Lai MJ, Lin NT, Hu A, Soo PC, Chen LK, Chen LH, Chang KC. 2011. Antibacterial activity of Acinetobacter baumannii phage varphiAB2 endolysin (LysAB2) against both gram-positive and gram-negative bacteria. Appl Microbiol Biotechnol 90:529-539. https://doi.org/10.1007/ s00253-011-3104-y.

26. Briers $Y$, Walmagh $M$, Van Puyenbroeck V, Cornelissen A, Cenens W, Aertsen A, Oliveira H, Azeredo J, Verween G, Pirnay JP, Miller S, Volckaert G, Lavigne R. 2014. Engineered endolysin-based "Artilysins" to combat multidrugresistant gram-negative pathogens. mBio 5:e01379-14. https://doi.org/10 .1128/mBio.01379-14.

27. Lood R, Winer BY, Pelzek AJ, Diez-Martinez R, Thandar M, Euler CW
Schuch R, Fischetti VA. 2015. Novel phage lysin capable of killing the multidrug-resistant Gram-negative bacterium Acinetobacter baumannii in a mouse bacteremia model. Antimicrob Agents Chemother 59: 1983-1991. https://doi.org/10.1128/AAC.04641-14.

28. Thandar M, Lood R, Winer BY, Deutsch DR, Euler CW, Fischetti VA. 2016 Novel engineered peptides of a phage lysin as effective antimicrobials against multidrug-resistant Acinetobacter baumannii. Antimicrob Agents Chemother 60:2671-2679. https://doi.org/10.1128/AAC.02972-15.

29. Larpin Y, Oechslin F, Moreillon P, Resch G, Entenza JM, Mancini S. 2018. In vitro characterization of PlyE146, a novel phage lysin that targets Gram-negative bacteria. PLoS One 13:e0192507. https://doi.org/10.1371/ journal.pone.0192507.

30. Vaara M. 1992. Agents that increase the permeability of the outer membrane. Microbiol Rev 56:395-411.

31. Williams BJ, Dehnbostel J, Blackwell TS. 2010. Pseudomonas aeruginosa: host defence in lung diseases. Respirology 15:1037-1056. https://doi .org/10.1111/j.1440-1843.2010.01819.x.

32. Clements JA. 1997. Lung surfactant: a personal perspective. Annu Rev Physiol 59:1-21. https://doi.org/10.1146/annurev.physiol.59.1.1.

33. Pastagia M, Euler C, Chahales P, Fuentes-Duculan J, Krueger JG, Fischetti VA. 2011. A novel chimeric lysin shows superiority to mupirocin for skin decolonization of methicillin-resistant and -sensitive Staphylococcus aureus strains. Antimicrob Agents Chemother 55:738-744. https://doi.org/ 10.1128/AAC.00890-10.

34. Pastagia M, Schuch R, Fischetti VA, Huang DB. 2013. Lysins: the arrival of pathogen-directed anti-infectives. J Med Microbiol 62:1506-1516. https://doi.org/10.1099/jmm.0.061028-0.

35. Hidron Al, Edwards JR, Patel J, Horan TC, Sievert DM, Pollock DA, Fridkin SK, National Healthcare Safety Network Team, Participating National Healthcare Safety Network Facilities. 2008. NHSN annual update: antimicrobial-resistant pathogens associated with healthcare-associated infections: annual summary of data reported to the National Healthcare Safety Network at the Centers for Disease Control and Prevention, 2006-2007. Infect Control Hosp Epidemiol 29:996-1011. https://doi.org/ $10.1086 / 591861$.

36. Osguthorpe JD, Nielsen DR. 2006. Otitis externa: review and clinical update. Am Fam Physician 74:1510-1516.

37. Galentine PG, Cohen EJ, Laibson PR, Adams CP, Michaud R, Arentsen JJ. 1984. Corneal ulcers associated with contact lens wear. Arch Ophthalmol 102:891-894. https://doi.org/10.1001/archopht.1984.01040030711025.

38. Briers $Y$, Walmagh M, Grymonprez B, Biebl M, Pirnay JP, Defraine V, Michiels J, Cenens W, Aertsen A, Miller S, Lavigne R. 2014. Art-175 is a highly efficient antibacterial against multidrug-resistant strains and persisters of Pseudomonas aeruginosa. Antimicrob Agents Chemother 58: 3774-3784. https://doi.org/10.1128/AAC.02668-14.

39. Defraine V, Schuermans J, Grymonprez B, Govers SK, Aertsen A, Fauvart M, Michiels J, Lavigne R, Briers Y. 2016. Efficacy of Artilysin Art-175 against resistant and persistent Acinetobacter baumannii. Antimicrob Agents Chemother 60:3480-3488. https://doi.org/10.1128/AAC .00285-16

40. Das S, MacDonald K, Chang HY, Mitzner W. 2013. A simple method of mouse lung intubation. J Vis Exp 2013:e50318. https://doi.org/10.3791/ 50318. 